\title{
Older-Worker Opportunity in the United Kingdom
}

\author{
By Natasha Oppenheim
}

$\mathbf{T}$ here is a great opportunity in the United Kingdom to harness the power of experienced workers. Even though older people have been identified as more vulnerable to the Covid-19 virus, and have therefore been advised to shield or self-isolate to a greater degree than other age groups, the fact remains that older workers are a rapidly increasing demographic in the United Kingdom that the government, as well as the public and private sectors, have identified as a key target for labor supply. We have an estimated 800,000 people aged 50 and over who would like to be in work but who are not - which our politicians have called an "unacceptable waste of talent". This comes amid projections of a labor and skills shortage of more than 5 million people in the United Kingdom by 2022.

However, this identification of an opportunity to harness experience has not yet translated into action for the individual older worker facing the job market today. This is to the detriment of employers and society where there is much to gain by taking action on this front.

\section{Growing Awareness}

At a government level, the importance of older workers is clear. "Aging Society" is one of the four Grand Challenges of the Department for Business, Energy, and Industrial Strategy, which states:

The UK population is ageing, as it is across the industrialised world. The prospect of longer lives will require people to plan their careers and retirement differently. We have an obligation to help our older citizens lead independent, fulfilled lives, continuing to contribute to society. If we succeed, we will create an economy which works for everyone, regardless of age. ${ }^{1}$

This outlook is reinforced by our Equality Act, passed in 2010 to consolidate and strengthen discrimination Acts from the prior 30 years, which protects workers from age discrimination in all aspects of their employment, including recruitment, employment terms and conditions, promotions and transfers, training, and dismissals.

At a corporate level, there is a growing awareness and evolving change in organizational outlook that a multigenerational workforce is not only a driver of increased productivity and revenues, but also a pragmatic necessity for the future of the workplace.
The future of the workplace has already been and will continue to be greatly affected by the Covid-19 pandemic. The requirement for remote-working has accelerated an already growing work-from-home trend. In theory this is a boon for older workers: it frees them up to re-enter the job market based on an assessment of their capabilities without physical restrictions - whether those restrictions were due to current advice around self-isolation, an individual's compromised mobility, or geographic limitations.

Nonetheless, significant ageism still exists in hiring older workers, who often feel excluded from the workplace. Evidence substantiates their feeling. In 2017, Anglia Ruskin University published the results of a study in which two sets of curriculum vitae (CVs) were submitted in response to almost 2,000 job advertisements across all types of positions. ${ }^{2}$ Half of the CVs were from a 28-year-old and the other half from a 50-year-old; otherwise the candidates had identical skills and interests. The study found that the 50-year-old candidate was four times less likely to be offered an interview.

Indeed, job placement in the United Kingdom for experienced workers is a difficult route to navigate. A large part of that difficulty stems from employers' divergent views of experienced workers: some see older workers as a cheap labor source, believing they are unlikely to get work anywhere else, while others have preconceptions that older workers are slower or harder to train, or that they won't fully commit to the job or stay in the position for long. However, some employers truly understand older workers' value, including the reliability, loyalty, mentoring and knowledge transfer, and these employers know how to benefit from older workers' contribution as part of an inclusive multigenerational workforce.

Yet even those employers who value experienced workers can have problems finding them. With increased rates of rejection, older workers in the United Kingdom often grow disillusioned with the most prominent job boards and stop using them. Additionally, older experienced candidates who do apply may be screened out in the application process either by software bias or by a younger initial CV screener, either in a recruitment company, or even within the company itself, who may hold preconceptions of older workers. Enterprises need to work on preventing such occurrences. 


\section{An Integrated Approach}

Addressing such ageism requires that many areas of employment evolve so that older workers can contribute fully: recruitment, retention, a focus on multigenerational staffing, and career longevity planning. Only through an integrated approach that addresses these issues and how they interact can we fully harness the power of older workers.

Advice for employers is lacking on how to spark this change, and where to turn for help in those efforts. This is where specialized companies such as No Desire to Retire and Experients can fill the gap: by providing not only a route for the employer to reach and employ the experienced worker, but also a route to navigate and incorporate other related issues. For example, how to fully incorporate age within a Diversity and Inclusion agenda and how to maximize the value of an experienced worker as part of a truly multigenerational organization.

It's not just the employers, of course, who need help. Experienced older workers themselves often need help with job seeking, advice on career development, and guidance on relevant skills and training. This difficulty in accessing a route back to work for older workers is further compounded by the real divide between different types of experienced older workers and the extent to which their role has been affected by automation over the previous decade. For example, many of those who have lost warehousing or factory jobs to automation have had difficulty identifying a transitional path to their next career.

This is where the concept of adjacency of skills and training can aid the transition to the next chapter in an older worker's career. An understanding of adjacency of skills - namely the identification of what skills have been gained over many decades of experience and how those skills might be used in a job that may be in a different role or industry - can be crucial to elongating the career of older workers. Training is likewise an integral part of increasing the number of experienced workers in employment - not only training to update existing skill sets and achieve the most current certification, but also training in skill identification and adjacent roles, plus any shifts in communication styles or workplace norms. During Covid-19, for example, we have seen a requirement for up-skilling in the technologies required for remote working.

\section{The Skill Advantage and Challenge}

However, one of the benefits of automation has been the enhanced focus on the need for soft skills, and it is in this area in which experienced workers have an advantage. Experienced workers outperform other age groups on almost every test of soft skills, from resilience to problem solving to mentoring. Additionally, the Covid-19 pandemic will result in opportunities for experienced workers to help industries facing unprecedented challenges to adapt by helping organizations navigate uncertainty based on their longer-term perspective and previous experience with similar scenarios. In the United Kingdom, where there is an increasing demand for soft skills and experience alongside an expanding supply of experienced older workers, the result is an increased opportunity for older workers. The consequence of that will be a triple win - for older workers, employers, and society as a whole.

Finding the people with the right skills to fill the labor gap is a challenge, but the solution lies with the millions of older experienced people looking to work. With an integrated approach of providing access to jobs and training for older workers, and by providing the integrated mindset and policies for employers that recognize the need and benefit of an age-inclusive and truly multigenerational workplace, the United Kingdom is well positioned to be a champion for experienced older workers in this new era of work. $\bullet$

${ }^{1}$ https://www.gov.uk/government/publications/industrial-strategythe-grand-challenges/industrial-strategy-the-grand-challenges

${ }^{2}$ https://aru.ac.uk/news/ageism-still-significant-in-uk-labour-market

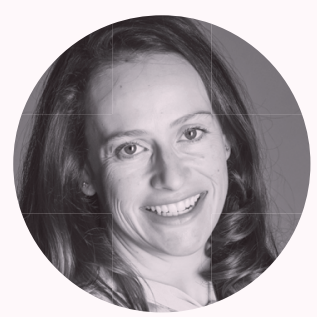

Natasha Oppenheim

CEO

No Desire to Retire 